\title{
Defining Zoledronate's Duration of Action and Optimal Dosing Interval for an Effective Therapy
}

\author{
Stuart L. Silverman
}

Published online: 16 December 2010

(C) The Author(s) 2010. This article is published with open access at Springerlink.com

\section{Trial}

Grey A, Boland M, Wattie D, et al.:Prolonged antiresorptive activity of zoledronate:a randomized control trial. Gen Bone Miner Res 2010, 25:2251-2255.

\section{Introduction}

Zoledronic acid (ZA) is a potent nitrogen-containing bisphosphonate with a long skeletal half-life that is administered annually by intravenous (IV) infusion. In the Horizon trial, ZA significantly reduced the risk of vertebral fracture by $70 \%$, the risk of hip fracture by $40 \%$, and the risk of nonvertebral fracture by $20 \%$ [1]. ZA also reduced the risk of clinical fracture by $35 \%$ and decreased mortality by $28 \%$ after hip fracture in the Recurrent Fracture Trial [2]. A combination of antifracture efficacy, low rate of adverse events, and infrequent dosing make it a desirable agent for the future.

\begin{abstract}
Aims
Defining the duration of action of zoledronate and the optimal dosing interval may help reduce the cost of an effective therapy.
\end{abstract}

\footnotetext{
S. L. Silverman $(\bowtie)$

Medical Director Cedars-Sinai Bone Center of Excellence,

David Geffen School of Medicine UCLA,

8641 Wilshire Boulevard, Suite 301,

Beverly Hills, CA 90211, USA

e-mail: stuarts@omcresearch.org
}

\section{Methods}

Andrew Grey performed a 3-year randomized placebocontrolled trial of the effects on bone turnover and bone mineral density (BMD) of a single infusion of $5 \mathrm{mg}$ IV zoledronate. Fifty postmenopausal women with osteoporosis were randomized to either a single infusion of IV ZA or placebo. The primary end points were bone turnover markers such as $\beta$ CTX (C telopeptide) and P1NP (procollagen type I N-terminal propeptide). Secondary end points were BMD of the lumbar spine, total hip, and total body. After 3 years, bone markers, serum $\beta$ CTX, and P1NP were $44 \%$ and $40 \%$ lower in the zoledronate group $(P<0.001$ vs placebo for each marker). BMD was higher in the zoledronate than in the placebo group by an average of $6.8 \%$ in the lumbar spine, $4.0 \%$ total hip, and $2.0 \%$ of total body $(P<0.001$ for each skeletal site). Between-group differences in makers of bone turnover and BMD were stable from 12 to 36 months.

\section{Discussion}

The data demonstrate the antiresorptive effects of a single 5-mg IV dose of zoledronate was sustained for 3 years and suggests we may wish to consider investigating the antifracture efficacy of ZA in dosing intervals longer than 1 year. However, it is important to note that the Horizon trial, which required IV once yearly for 3 years, is the only trial that has shown fracture efficacy as an end point in the treatment of patients at risk for osteoporotic fracture.

A recent report by Black et al. [3] at the 2010 American Society for Bone and Mineral Research Meeting in Toronto of a 3-year extension of the Horizon trial addresses another related issue, the possibility of a holiday after 3 years 
treatment. Black et al. [3] identified 1,233 patients in the Horizon trial at year 3 who were randomized to either continued infusions of IV ZA or placebo. BMD remained constant at all sites in the 6-year ZA group, whereas there was a slight drop in femoral neck BMD of about $1 \%$ in the group that received 3 years of placebo injection after 3 years of ZA but the BMD remained well above pretreatment levels.. Results for other sites of BMD were similar. Biochemical markers remained constant in the group receiving ZA for 6 years but rose slightly in the group receiving placebo for 3 years. New morphometric vertebral fractures were significantly lower in the group receiving six $\mathrm{ZA}$ injections $(\mathrm{RR}=0.48, P=0.04)$, whereas other categories of fractures including nonvertebral, hip, and clinical vertebral were not different between study groups.

\section{Conclusions}

The data demonstrate that the antiresorptive effect of IV ZA is sustained for 3 years. Future studies of different dosing intervals may be considered. However, for now we do know that once-yearly IV ZA for 3 years is effective in reducing fracture risk.

Disclosure Conflicts of interest: S.L. Silverman: has received grant support from Novartis.

Open Access This article is distributed under the terms of the Creative Commons Attribution Noncommercial License which permits any noncommercial use, distribution, and reproduction in any medium, provided the original author(s) and source are credited.

\section{References}

1. Black DM, Delmas PD, Eastell R, et al.: Once-yearly zoledronic acid for treatment of postmenopausal osteoporosis. N Engl J Med. 2007 May 3;356(18):1809-22.

2. Lyles KW, Colón-Emeric CS, Magaziner JS, et al.: Zoledronic Acid in Reducing Clinical Fracture and Mortality after Hip Fracture. N Engl J Med. 2007;357:nihpa40967.

3. Black DM, et al: The effect of 3 versus 6 years of Zoledronic acid treatment in osteoporosis: a randomized extension to the Horizon Pivotal Fracture Trial. Presented at the American Society for Bone and Mineral Research 2010 Annual Meeting. Toronto, Canada; October 15-19, 2010. 